\title{
Mide kanserli hastalarda adjuvan kemoradyoterapi: Tek merkez deneyimi
}

\author{
Adjuvant chemoradiotherapy in patients with gastric cancer: Single-center experience \\ Birsen YÜCEL ${ }^{1}$, Ebru ATASEVER AKKAŞ ${ }^{1}$, Yllar OKUR ${ }^{1}$, Nalan BABACAN², Mehmet Fuat EREN ${ }^{1}$, Turgut KAÇAN², \\ Saadettin KILIÇKAP \\ Cumhuriyet Üniversitesi Tip Fakültesi, ${ }^{1}$ Radyasyon Onkolojisi Anabilim Dalı, ${ }^{2}$ Tıbbi Onkoloji Bilim Dall, Sivas
}

\begin{abstract}
Giriş ve Amaç: Bu çalışmada, adjuvan kemoradyoterapi ile tedavi edilen mide kanserli hastaların sağkalım analizi, tedavi yan etkileri ve sağkalımı etkileyen prognostik faktörlerin incelemesi amaçlandı. Gereç ve Yöntem: Çalışmada Cumhuriyet Üniversitesi Tip Fakültesi Arasstırma ve Uygulama Hastanesi Onkoloji Merkezinde takip edilen 90 mide kanserli hasta verileri retrospektif olarak incelendi. Bulgular: Calışmada 68 (\%76) erkek, 22 (\%24) kadın toplam 90 hastanın verileri analiz edildi. Ortanca takip süresi 19 ay (4-105 ay) idi. Iki yıllık genel sağkalım ve hastalıksız sağkalım sırasıla \%62 ve \%58 idi. Tek değişkenli analizde hastaların sağkalımını grade (p:0,039), T evre (p:0,001), N evre (p:0,020), kilo kaybı (p: 0,001), ECOG performans duru$m u$ (p:0,002), anemi (p:0,019), hipoalbunemi (p:0,001) etkilerken, çok değişkenli analizde bağımsız prognostik faktörler kilo kaybı (p:0,008), T evresi (p:0,024) ve ECOG performans durumu (p:0,033) idi. Hastalarda en sik görülen yan etkiler; bulantı-kusma 66 (\%73), dispepsi 52 (\%58), anemi 45 (\%50), nötropeni 36 (\%40), ishal 34 (\%38) ve kilo kaybı 29 (\%32) hastada görüldü. Sonuç: Bu çalışmada, adjuvan kemoradyoterapi uygulanan mide kanserli hastaların genel ve hastalıksız sağkalımı literatür ile benzer sonuçlar göstermiştir. Bu hasta grubunun en önemli prognostik faktörleri ise kilo kaybi, T evresi ve ECOG performans durumu olarak belirlendi.
\end{abstract}

Anahtar kelimeler: Mide kanseri, kemoradyoterapi, sağkalım, prognoz

\section{GİRIS}

Mide kanseri görülme sıklığı son yıllarda azalmasına rağmen, halen dünyada kansere bağlı en sık ölüm nedenlerinden biridir (1). Hastalığın görülme sıklığı Japonya'da, Doğu Asya'da, Güney Amerika'da ve Doğu Avrupa'da fazladır (2). Türkiye'de ise, 2005 yılı T.C. Sağlık Bakanlığı Kanserle Savaş Dairesi Başkanlığı verilerine göre kanserler arasında görülme sıklığı açısindan 5. sirada yer almaktadır (3).

Cerrahi tedavi potansiyel olarak rezektabl tümörler için uygun bir seçenektir. Radikal cerrahi sonrası küratif tedavi ancak olguların \%50'sinde uygulanabilirken, tedavi verilebilen hastaların \%50'sinde ise lokal nüks görülmektedir (4). Tek başına cerrahi tedavi sonuçlarının yeterince yüz güldürücü olmaması nedeniyle adjuvan tedaviye ihtiyaç vardır. The American Intergroup çalışması (INT-0116), adjuvan kemoradyoterapinin yararını gösteren ilk geniş çalışmadır (5). Bu çalışmada, MacDonald ve arkadaşları tek başına cerrahi tedaviye karşı post-operatif kemoradyoterapinin hem genel hem de hastalıksız sağkalımda düzelme sağladığını göstermiştir.
Background/aims: The purpose of this study was to review survival analysis, side effects and prognostic factors in patients with gastric cancer who were treated with adjuvant chemoradiotherapy. Materials and Methods: In this study, we retrospectively evaluated the data of 90 patients with gastric cancer followed at Cumhuriyet University Faculty of Medicine, Oncology Center. Results: This study analyzed the data of 90 patients (68 (76\%) males, 22 (24\%) females). The median follow-up was 19 months (range: 4-105). The two-year overall and disease-free survival rates were $62 \%$ and $58 \%$, respectively. In univariate analysis, the factors that determined survival were grade ( $p: 0.039), T$ (p: 0.001) and $N(p: 0.020)$ stages, weight loss (p: 0.001), Eastern Cooperative Oncology Group performance status (p: 0.002), anemia (p: 0.019), and hypoalbuminemia ( $p: 0.001$ ). After multivariate analysis, weight loss ( $p$ : 0.008), I stage (p: 0.024) and Eastern Cooperative Oncology Group performance status ( $p: 0.033)$ were determined as indepenent prognostic factors that affect survival. The most frequent side effects were nausea and vomiting in 66 patients (73\%), dyspepsia in 52 patients (58\%), anemia in 45 patients (50\%), neutropenia in 36 patients (40\%), diarrhea in 34 patients (38\%), and weight loss in 29 patients (32\%). Conclusions: It was shown that the overall survival and disease-free survival in non-metastatic gastric cancer patients who received adjuvant chemoradiotherapy complied with the literature.

Key words: Gastric cancer, chemoradiotherapy, survival, prognosis

Bu çalışmadan sonra birçok merkezde metastazı olmayan evre IB-IV hastalıkta adjuvan kemoradyoterapi standart tedavi olarak kabul görmüştür. Son yayınlanan uluslar arası kılavuzlarda (National Comprehensive Cancer Network Guideline 2011 version 2) da evre IB hastalık evresinden ileri metastatik evre hariç tüm evrelerde postoperatif kemoradyoterapiyi önermektedir (6).

Bu çalışmada, 2006-2011 yılları arasında merkezimizde postoperatif kemoradyoterapi uygulanan hastaların sağkalım analizi, yan etkilerin değerlendirilmesi ve sağkalımı etkileyen prognostik faktörlerin araştırılması amaçlanmıştır.

\section{GEREÇ ve YÖNTEM}

Cumhuriyet Üniversitesi Tıp Fakültesi Eğitim Araştırma ve Uygulama Hastanesi Radyasyon Onkolojisi Anabilim Dalına ve Tıbbı Onkoloji Bilim Dalına 2006-2011 tarihleri arasında başvuran ve mide kanseri tanısı ile postoperatif kemoradyoterapi uygulanan hastalara ait demografik, klinik ve histopato- 
lojik veriler, hasta dosya ve hastane kayıtlan incelenerek elde edildi. Tüm hastalar için İl Nüfus Müdürlügünden izin alınarak kimlik sorgulama sisteminden hastaların yaşayı yaşamadıkları öğrenilerek kaydedildi.

Hastaların performans durumu hasta başvurusunda Eastern Cooperative Oncology Group (ECOG) skorlama sistemine göre değerlendirildi. Anemi için hemoglobin değeri 12 g/dl'den, hipoalbuminemi için 3,2 g/dl'den düşük değerlere sahip hastalar, kilo kaybı için de ayda kilosunun \%10'dan fazlasını kaybeden hastalar alındı. Hastalık evresi 2010 International Union Against Cancer/American Joint Committee On Cancer (UICC/AJCC) TNM sinıflamasına göre yapıldı.

Hastalara cerrahiden sonra adjuvan olarak 2 kür kemoterapi sonrası kemoterapi ile kombine radyoterapi uygulandı. Kemoterapi, radyoterapinin ilk 4 günü ve son 3 günü olarak uygulanırken, kemoterapi rejimi 5 fluorourasil $425 \mathrm{mg} / \mathrm{m}^{2}$ ve kalsiyum folinat $20 \mathrm{mg} / \mathrm{m}^{2}$ şeklindeydi. Radyoterapi 180 cGy günlük fraksiyon ile toplam 25 fraksiyon, 18 MV foton enerjisi ile linac cihazında uygulandı. Kemoradyoterapiden sonra hastalara 1 kür daha kemoterapi verildi. Tedavi sırasında haftada bir, takiplerde de 3 ayda bir Radiotio Therapy Oncology Group (RTOG) kriterlerine göre yan etki değerlendirilmesi yapıldı. Endoskopik biyopsi ile tanı konulduğu zaman, takip başlangıç süresi olarak değerlendirilmiştir.

Analiz için SPSS version 14.0 ile siklık testleri, Mann-Whitney U testi ve Kaplan-Meier analizi kullanıldı. Sağkalım üzerine etkili olan bağımsız faktörleri değerlendirmek amacıyla çok değişkenli analiz (Cox regresyon analizi) yapıldı. P değeri $\leq 0.05$ olması istatistiksel olarak anlamlı kabul edildi. Çalışma öncesinde verilerin toplanması, değerlendirilmesi, analizi ve yorumlanabilmesi için Cumhuriyet Üniversitesi Tıp Fakültesi Etik Kurulu'ndan onay alınd.

\section{BULGULAR}

Bu çalışmada 68'ı (\%76) erkek ve 22'si (\%24) kadın toplam 90 hastaya ait veriler analiz edildi. Hastaların ortanca yaşı 59 (31-85), erkek hastalarda 60 (31-75), kadın hastalarda ise 57 (34-73) olup cinsiyetler için ortanca yaş yönünden fark bulunmamaktaydı (p:0,293). Ailede kanser hikâyesi 23 (\%26), sigara kullanımı 41 (\%46) ve komorbitide 21 (\%23) hastada pozitif olarak bulundu. ECOG performans durumu: ECOG0 61 (\%68) ve ECOG1 29 (\%32) hastada tespit edildi. Hastaların hemoglobin değeri incelendiğinde 38'inde (\%42) 12g/dl'den az, albumin değeri ise 25 'inde (\%28) 3,2g/dl az idi. Preoperatif CEA yüksekliği 10 (\%17), Ca19,9 yüksekliği ise 10 (\%16) hastada bulunmaktaydı.

Tümör lokalizasyonuna göre midenin proksimal (kardia, fundus) kısmında 17 (\%19), gövde (korpus, küçük ve büyük kurvatur) kısmında 24 (\%27), distal (antrum, pilor) kismında ise 49 (\%54) hastada görüldü. Otuz beş (\%39) hastaya subtotal gastrektomi, 50 (\%55) hastaya total gastrektomi, 5 (\%6) has- taya da sadece biyopsi uygulandı. Hastaların 22'sinde (\%24) yetersiz lenf nodu disseksiyonu (çıkarılan lenf nodu sayısı <15) mevcutken, ortanca çıkarılan lenf nodu sayısı 20 (4-71), ortanca tutulan lenf nodu sayısı 4 (0-44) idi. Histopatolojik tanıları incelendiğinde, adenokarsinom 76 (\%84) hastada ve 14 (\%16) hastada taşlı yüzük hücreli karsinom tespit edildi. GradeI 12 (\%14) hastada, gradeII 39 (\%47) hastada ve gradeIII 32 (\%39) hastada mevcuttu. Perinöral invazyon (PNI) 44 (\%58) hastada, lenfovasküler invazyon (LVI) 53 (\%70) hastada, ekstrakapsüler invazyon 29 (\%32) hastada pozitif idi.

Hastaların 7'sinde (\%8) evreIB, 16'sinda (\%18) evreIIA, 15'inde (\%16) evreIIB, 20'sinde (\%22) evreIIIA, 25'inde (\%28) evreIIIB, 7'sinde (\%8) ise evreIIIC bulunmaktaydı. Beş (\%6) hastada T1, 20 (\%22) hastada T2, 52 (\%58) hastada T3, 13 (\% 14) hastada T4; 13 (\%14) hastada N0, 18 (\%20) hastada N1, 27 (\%30) hastada N2, 32 (\%36) hastada N3 hastalık mevcuttu. Hastaların klinikopatolojik ve demografik özellikleri Tablol'de görülmektedir.

\begin{tabular}{|c|c|c|}
\hline & Hasta sayısı & $\%$ \\
\hline $\begin{array}{l}\text { Hastaya ait özellikler } \\
\text { Erkek } \\
\text { Kadın }\end{array}$ & $\begin{array}{l}68 \\
22\end{array}$ & $\begin{array}{l}76 \\
24\end{array}$ \\
\hline $\begin{array}{l}\text { Ailede kanser hikayesi } \\
\text { Sigara } \\
\text { Komorbidite }\end{array}$ & $\begin{array}{l}23 \\
41 \\
21\end{array}$ & $\begin{array}{l}26 \\
46 \\
23\end{array}$ \\
\hline $\begin{array}{l}\text { ECOG0 } \\
\text { ECOG1 }\end{array}$ & $\begin{array}{l}62 \\
28\end{array}$ & $\begin{array}{l}69 \\
31\end{array}$ \\
\hline $\begin{array}{l}\text { Lokalizasyon } \\
\text { Fundus, kardia } \\
\text { Korpus } \\
\text { Antrum, pilor }\end{array}$ & $\begin{array}{l}17 \\
24 \\
49\end{array}$ & $\begin{array}{l}19 \\
27 \\
54\end{array}$ \\
\hline $\begin{array}{l}\text { Cerrahi tipi } \\
\text { Subtotal gastrektomi } \\
\text { Total gastrektomi } \\
\text { Biyopsi }\end{array}$ & $\begin{array}{l}38 \\
50 \\
5\end{array}$ & $\begin{array}{c}39 \\
55 \\
6\end{array}$ \\
\hline $\begin{array}{l}\text { Laboratuvar bulguları } \\
\text { Anemi }(<12 \mathrm{~g} / \mathrm{dl}) \\
\text { Hipoalbunemi }(<3,2 \mathrm{~g} / \mathrm{dl}) \\
\text { CEA yüksekliği } \\
\text { Ca19,9 yüksekliği }\end{array}$ & $\begin{array}{l}38 \\
25 \\
10 \\
10\end{array}$ & $\begin{array}{l}42 \\
28 \\
17 \\
16\end{array}$ \\
\hline $\begin{array}{l}\text { Histopatoloji } \\
\text { Adenokarsinom } \\
\text { Taşlı yüzük hücreli }\end{array}$ & $\begin{array}{l}76 \\
14\end{array}$ & $\begin{array}{l}84 \\
16\end{array}$ \\
\hline $\begin{array}{l}\text { Perinöral invazyon } \\
\text { Lenfovasküler invazyon } \\
\text { Ekstrakapsüler invazyon }\end{array}$ & $\begin{array}{l}44 \\
53 \\
29\end{array}$ & $\begin{array}{l}58 \\
70 \\
32\end{array}$ \\
\hline $\begin{array}{l}\text { GradeI } \\
\text { GradeII } \\
\text { GradeIII }\end{array}$ & $\begin{array}{l}12 \\
39 \\
32\end{array}$ & $\begin{array}{l}14 \\
47 \\
39\end{array}$ \\
\hline $\begin{array}{l}\text { Evre } \\
\text { EvreI } \\
\text { EvreII } \\
\text { EvreIII }\end{array}$ & $\begin{array}{c}7 \\
31 \\
52\end{array}$ & $\begin{array}{c}8 \\
34 \\
58\end{array}$ \\
\hline Ortanca tutulan lenf nodu & 4( & \\
\hline Ortanca çıkarılan lenf nodu & 20 & \\
\hline
\end{tabular}


Hastalar ortanca 19 ay (4-105 ay) takip edildiler. Iki ylllık genel sağkalım ve hastalıksız sağkalım sırasıyla \%62 ve \%58 olarak kaydedildi. Takipteki hastaların 14'ünde (\%16) lokal rekürrens, 19'unda (\%21) uzak metastaz teşhis edildi. Metastazlar siklıkla karaciğere (13 hastada tüm metastazların \%68'ini oluşturmaktaydı) olmuştur.

Üç (\%3) hasta kemoradyoterapiyi tamamlayamazken, 9 (\%10) hasta da yan etkiler nedeniyle tedaviye ara verildi. Tedavi yan etkisi olarak sıklık sırasına göre: 66 (\%73) hastada bulant1, kusma, 52 (\%58) hastada dispepsi, 45 (\%50) hastada anemi, 34 (\%38) hastada ishal, 36 (\%40) hastada nötropeni, 29 (\%32) hastada tedaviye bağlı kilo kaybı, 12 (\%13) hastada mukozit, 11 (\%12) hastada yutma güçlüğü, 9 (\%10) hastada trombositopeni, 3 (\%3) hastada radyoterapi enteriti gelişti. Tedaviye bağlı yan etkiler ve gradi Tablo2'de görülmektedir.

\begin{tabular}{|c|c|c|}
\hline Yan etkiler & $\begin{array}{l}\text { GradeI-II yan etki } \\
\text { Hasta sayısı (\%) }\end{array}$ & $\begin{array}{c}\text { GradeIII-IV yan etki } \\
\text { Hasta sayısı (\%) }\end{array}$ \\
\hline Nötropeni & $25(28)$ & $11(12)$ \\
\hline Anemi & $38(42)$ & $7(8)$ \\
\hline Trombositopeni & $9(10)$ & - \\
\hline Mukozit & $12(13)$ & - \\
\hline $\begin{array}{l}\text { Üst gastrointestin } \\
\text { *Bulant1-kusma } \\
\text { *Dispepsi }\end{array}$ & $\begin{array}{l}54(60) \\
37(41)\end{array}$ & $\begin{array}{l}12(13) \\
15(17)\end{array}$ \\
\hline Yutma güçlüğü & $11(12)$ & - \\
\hline Ishal & $34(38)$ & - \\
\hline Radyoenterit & - & $3(3)$ \\
\hline Kilo kaybı & $\begin{array}{c}16 \text { (\%17) hastada } 5 \mathrm{~kg} \\
\text { ve altı kilo kaybı }\end{array}$ & $\begin{array}{c}13 \text { (\%14) hastada } 5 \text { kg } \\
\text { üzeri kilo kaybı }\end{array}$ \\
\hline
\end{tabular}

Hastaların sağkalım analizinde, tek değişkenli analizde, sağkalımı etkileyen faktörler: grade (p:0,039), ECOG performans durumu (p:0,002), anemi (p:0,019), hipoalbüminemi (p:0,001), kilo kaybi (p:0,001), T evresi (p:0,001) ve N evresi (p:0,020) idi. Cinsiyet (p.0,404), komorbidite (p:0,639), histopatoloji $(0,846)$, PNI (p:0,737), LVI $(0,088)$, ekstrakapsüler invazyon $(0,065)$, yerleşim yeri (p:0,452), CEA (p:0,178) ve Ca19,9 (p:0,120) yüksekliği sağkalımı etkilememekteydi. Çok değişkenli analizde ise bağımsız prognostik faktörler kilo kaybı [p:0,008 RR (\%95 güven aralığında): $2,82]$ ve $\mathrm{T}$ evre [p:0,005 RR (\%95 güven aralığında): 3,79 ] ve ECOG performans durumu [p:0,033 RR (\%95 güven aralığında): 2,32] olarak tespit edildi. Kilo kaybı, T evre ve ECOG performans durumuna göre sağkalım eğrileri Şekil 1,2 ve 3'de görülmektedir.

\section{TARTIŞMA}

Mide karsinomaları yüksek mortalite oranları ile birlikte dünyada sık görülen kanserlerden biridir (7). Küratif cerrahiye

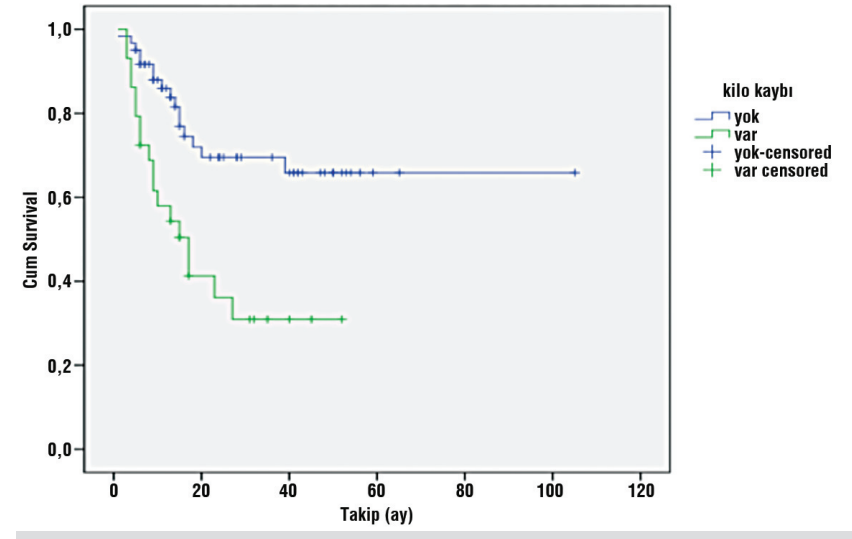

Şekil 1. Kilo kaybına göre sağkalım eğrisi.

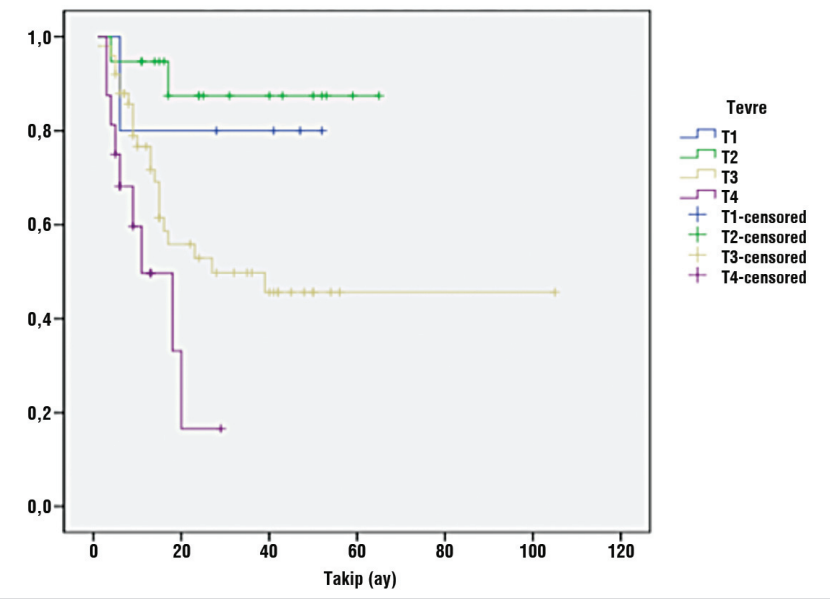

Şekil 2. T evresine göre sağkalım eğrisi.

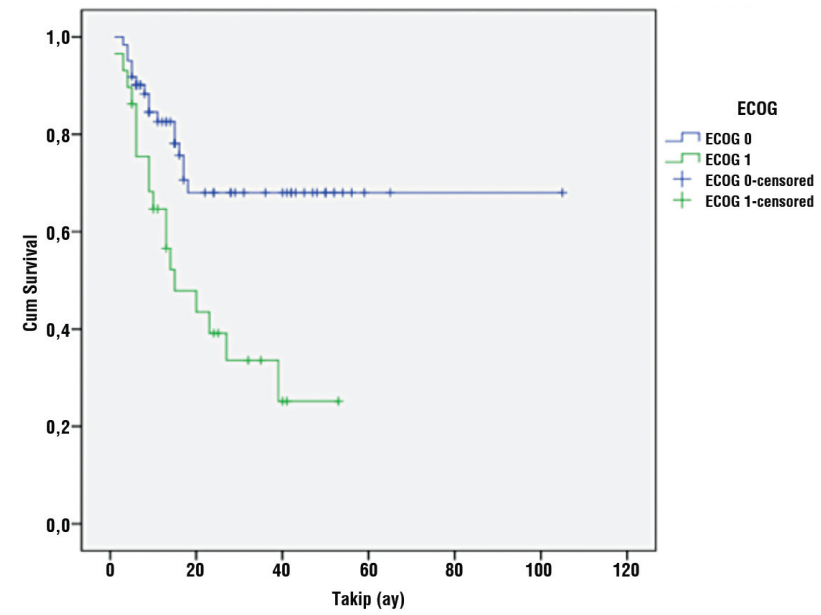

Şekil 3. ECOG performans durumuna göre sağkalım eğrisi.

rağmen hastaların çoğunda lokal ve uzak metastatik hastalık gelişmektedir. Nüks ve metastazda ise hastaların mortaliteleri oldukça yüksek olmaktadır. Bu nedenle de klinik çalışmalarnn temel hedefi adjuvan tedavilerle, nüks ve metastaz riskini azaltmak olmuștur. 
Hermans ve ark.ları cerrahi tedaviye karşı adjuvan kemoterapiyi karşılaştıran 11 randomize çalışmanın meta-analizin de sağkalım avantajı bildirmemişlerdir (8). Daha sonra yapılan meta-analizde ise adjuvan kemoterapinin istatistiksel olarak küçük bir sağkalım avantajı sağladığı gösterilmiştir (9). Cerrahiden sonra lokal ve uzak metastazlar nedeniyle sağkalımın iyi olmaması, adjuvan kemoterapinin yeterince iyi sonuç vermemesinden dolayı adjuvan tedavide radyoterapinin yeri araştırılmaya başlanmıştır. British Stomach Cancer Group randomize bir çalışmada cerrahiye karşı adjuvan radyoterapinin veya kemoterapinin sağkalım yararını gösterememişlerdir. Çalışmanın sonucunda, 5 yıllık genel sağkalım cerrahi tedavide $\% 20$, cerrahiden sonra radyoterapi uygulananlarda $\% 12$, cerrahi sonrası kemoterapi uygulananlarda ise \%19 olup istatistiksel olarak arada fark bulunmamıştır (10).

Adjuvan kemoradyoterapinin yerini araştıran ilk büyük çalışma INT-0116 çalışmasıdır. Bu çalışmada, 556 seçilmiş hastanın 281'ine cerrahiden sonra 5-fuorourasil/leucovorin, ile birlikte 45 Gy/1,8 Gy günlük radyoterapi, 275'ine ise cerrahiden sonra sadece izlem yapılmıştır. Çalışmaya metastazı olmayan evre IB-IV hastalar dahil edilmiş ve her iki kolda da hastaların $\% 85$ 'inde lenf nodu pozitif idi (evre IIIA, IIIB, non metastatik evre IV). Hastaların \%54'ine D0 diseksiyon, \%10'una da D2 diseksiyon uygulanmıştır. Çalışma 2001 yılında ortanca 5 yıllik takip sonuçları ile birlikte sunulmuştur (5). Daha sonra da 2004 yılında çalışma sonuçları up-date edilerek ortanca 7 yıllık sonuçlar bildirilmiştir (11). Ortanca 5 ylllık takipten sonra 3 ylllık genel sağkalım kemoradyoterapi alan hastalarda \%50, cerrahi alanlarda ise \%41, aradaki fark istatistiksel olarak anlamlı bulunmuştur (p:0,005). Üç ylllık hastalıksız sağkalım kemoradyoterapi kolunda \%48, cerrahi kolunda \%31 (p:<0,001), ortanca sağkalım ise kemoradyoterapi kolunda 36 ay, cerrahi kolunda 27 ay olarak tespit edilmiştir. Çalışmamızda, ortanca 19 ay takip ile 2 yllık genel sağkalım \%62, 2 yıllık hastalıksız sağkalım ise \%58 olup çalışmaya benzer sonuçlar elde edildi. Ortanca sağkalıma ise henüz ulaşılamadı.

Kim ve ark.ları (Kore çalışması) D2 nodal disseksiyon yapılan 544 hastaya postoperatif kemoradyoterapi, 466 hastaya da sadece cerrahi tedavi uygulamışlardır. Bu çalışmada da sonuçlar, adjuvan kemoradyoterapinin sağkalımı düzelttiğini göstermiştir. Üç yıllık genel sağkalım kemoradyoterapi kolunda \%65, hastalıksız sağkalım ise \%61 olarak tespit edilmiştir (12). Çalışmamıza dahil edilen hastaların özellikle kendi Üniversitemiz dışından gönderilen vakalardan yeterince bilgi alınamaması nedeniyle nodal disseksiyon durumunu belirtemedik. Ancak ortanca disseke edilen lenf nodu sayısı 20 (4-71) idi ve 22 (\%24) hastada yetersiz disseksiyon (<15) mevcuttu. Yetersiz disseksiyon mevcut sonucumuzu etkilemiş olabilir. Lokal rekürrens INT-0116 çalışmasında \%19, Kore çalışmasinda \% 14,9, çalışmamızda ise \% 16; uzak metastaz INT-0116 çalışmasında \%33, çalışmamızda \%21 olarak tespit edildi.

Kombine tedavilerin beraberinde getirdikleri sorunlardan bir tanesi de yan etkilerin artmasıdır. Hem INT-0116 çalışması hem de Kore çalışmasında grade 3-4 toksisite cerrahiye göre daha fazla görülmüştür. Grade 3-4 gastrointestinal yan etki INT-0116 çalışmasında \%33, Kore çalışmasında ise \%15 olarak bildirilmiştir $(5,12)$. Çalışmamızda grade 3-4 gastrointestinal yan etkiler \%17 hastada görülürken grade 1-2 gastrointestinal yan etki hastaların \%80'nından fazlasında tespit edildi. Grade 3-4 hematolojik toksisite INT-0116 çalışmasında sık görülmüştü (\%54 hastada) ve en sık görülen hematolojik toksisite de nötropeni olarak kaydedilmişti. Kore çalışmasında ise \%29 oranında grade 3-4 hematolojik toksisite mevcuttu. Çalışmamızda grade 3-4 hematolojik toksisite \%17 hastada ve sıklıkla da nötropeni görüldü. Grade 1-2 hematolojik toksisiteden ise en sık anemi tespit edildi. Yine çalışmamızda sık olarak görülen yan etki bulantı-kusma, dispepsi şikayetleri nedeniyle hastalarda oluşan kilo kaybı oldu. Hastaların \%17'sinde $5 \mathrm{~kg}$ ve altı, \%14'ünde $5 \mathrm{~kg}$ üzeri kilo kaybı mevcuttu. Altı aydan sonra \%3 hastamızda cerrahi müdahale gerektirecek radyoterapi enteriti gelişti. Hastalarımızın \%3'ü tedaviyi tamamlayamazken, \%10 hastada yan etki nedeniyle tedaviye ara verildi. INT-0116 çalışmasında tedaviyi tamamlayamayan hasta oranı \%17 iken, Kore çalışmasında \%10 olmuştur. Çalışmamamıda, toksisitesi yüksek olan bu tedavide, yan etkilerin kontrolü, yakın takip, destekleyici tedaviler ve tüm hastalara 3 boyutlu planlama yapılmasıyla biraz daha iyi sağlanabildi.

Birçok çalışmada tümörün mide duvarına invazyon derinliği (T evresi) ve lenf nodu tutulumu önemli prognostik faktörler olarak görülmektedir (12-14). Hochwald ve ark.ları (14) çok değişkenli analizde pozitif lenf nodu sayısının en önemli prognostik faktör olduğunu tespit etmişlerdir. Gunji ve ark.ları 4 ve üzeri lenf nodu pozitif olan erken mide kanserli hastalarda rekürrens olasılığının oldukça yüksek olduğunu ve sağkalımın kısaldığını bulmuşlardır (15). Marchet ve ark.ları D1, D2 ve D3 disseksiyon yapılmış 1853 mide kanserli hastaların analizinde disseksiyon tipine ve lenf nodu sayısina bakılmaksızın hastaları çıkarılan lenf nodu sayısına göre iki gruba ayırmışlardır (grup I <15 çıkarılan lenf nodu 1421 hasta ve grup II >15 çıkarılan lenf nodu 432 hasta). Grup I tek değişkenli analizde yaş (70 altı ve üstü), midede yerleşimi, cerrahi tipi, grade, T durumu, lenf nodunun anatomik yeri ve sayısı, grup II de cinsiyet, yaş, midede yerleşimi, cerrahi tipi, T durumu, lenf nodunun anatomik yeri ve sayısını da prognostik olarak önemli bulmuşlardır (16). Çalışmamızda tek değişkenli analizde, grade, N evresi, T evresi, kilo kaybı, ECOG performans durumu, anemi, hipoalbunemi hastaların sağkalımını etkileyen prognostik faktörlerdi. Bağımsız prognostik faktörler ise, kilo kaybı, T evresi ve hastaların ECOG performans durumu olarak tespit edildi.

Çalışmamızda da diğer çalışmalara benzer olarak mide kanserlerinde adjuvan kemoradyoterapi kabul edilebilir yan etkilerle beraber genel sağkalım ve hastalıksız sağkalımda düzelme göstermiştir. Bu hastalarda en önemli prognostik faktörler kilo kaybı, T evresi ve ECOG performans durumu olmuştur. 


\section{KAYNAKLAR}

1. Jemal A, Siegel R, Xu J, Ward E. Cancer statistics, 2010. CA Cancer J Clin 2010;60:277-300.

2. Dicken BJ, Bigam DL, Cass C, et al. Gastric adenocarcinoma. Ann Surg 2005;241:27-39.

3. Yilmaz HH, Yazihan N, Tunca D, et al. Cancer trends and incidence and mortality patterns in Turkey. Jpn J Clin Oncol 2010;41:10-6.

4. Wanebo H, Kenedy BJ, Chmiel J, et al. Cancer of the stomach: a patients care study by the American College of surgeons. Ann Surg 1993;218:583-92.

5. MacDonald JS, Smalley SR, Benedetti J, et al. Chemoradiotherapy after surgery compared with surgery alone for adenocarcinoma of the stomach or gastrointestinal junction. N Engl J Med 2001;345:725-30.

6. http://www.nccn.org/professionals/physician_gls/pdf/gastric.pdf (erișim tarihi: 20.02.2012)

7. Crew KD, Neugut Al. Epidemiology of gastric carcinoma. World J Gastroenterol 2006;12:354-62.

8. Hermans J, Bonenkamp JJ, Boon MC, et al. Adjuvant therapy after curative resection for gastric cancer: meta-analysis of randomized trials. J Clin Oncol 1993;11:1441-7.

9. Earl CC, Maroun JA. Adjuvantt chemotherapy after curative resection for gastric cancer in non-Asian patients: revisting a meta-analysis for randomized trials. Eur J Cancer 1999;36:1059-64.
10. Hallisley MT, Dunn JA, Ward LC, Allum WH. The second British Stomach Cancer Group trial of adjuvant radiotherapy or chemoterapy in resectable gastric cancer: five-year follow-up. Lancet 1994;343:1309-12.

11. MacDonald J, Smalley S, Benedetti J, et al. Postoperative combined radiation and chemotherapy improves disease-free survival (DFS) and overall survival (OS) in resected adenocarcinoma of the stomach and gastroesophageal junction. Update od the results of Intergroup Study INT0116 (SWOG 9008) [abstract]. Proc Am Soc Clin Oncol 2005:106.

12. Kim S, Lim DH, Lee J, et al. An observational study suggesting clinical benefit for adjuvantt postoperative chemoradiation in a population of over 500 cases after gastric resection with D2 nodal dissection for adenocarcinoma of stomach. Int J Radiat Oncol Biol Phys 2005;63:1279-85.

13. Okajima K. Prognostic factors of gastric cancer patients a study by univariate analysis (in Japanese, with English abstract). Jpn J Gastroenterol Surg 1997;30:700-11.

14. Hochwald SN, Kim S, Klimstra DS, et al. Analysis of 154 actual 5-year survivors of gastric cancer. J Gastrointest Surg 2000;4:520-5.

15. Gunji Y, Suzuki T, Hori S, et al. Prognostic significance of the number of metastatic lymph nodes in early gastric cancer. Dig Surg 2003;20:148-53.

16. Marchet A, Mocellin S, Ambrosi A, et al. Italian Research Group for Gastric Cancer (IRGGC). The ratio between metastatic and examined lymph nodes ( $\mathrm{N}$ ratio) is an independent prognostic factor in gastric cancer regardless of the type of lymphadenectomy: Results from an Italian multicentric study in 1853 patients. Ann Surg 2007;245:543-52. 